\title{
Amalú perdió un botón. De instrumento de juego a recurso para estimular y trabajar la percepción visual
}

\section{Daniel Villalobos Gamboa}

Diseñador gráfico, ilustrador y docente universitario, Máster en Tecnología Educativa de la Universidad Estatal a Distancia, UNED. Coordinador del Departamento de Edición de la Editorial EUNED; dvillalobos@uned.ac.cr

Recibido: 15 de octubre del 2013

\section{RESUMEN}

En este artículo se describe cómo las teorías de especialistas en lúdica, percepción visual y aprendizaje, fortalecen un instrumento doméstico de juego y lo transforman en una herramienta para estimular a las niñas y los niños que hoy crecen en una sociedad generosamente visual y así ayudarles a agudizar sus sentidos con el fin de que realicen una mejor lectura del mundo.

\section{PALABRAS CLAVE}

Percepción visual, aprendizaje visual, lúdica, producción de libros, metáfora global, imaginación simbólica.
Aceptado: 28 de enero del 2014

\section{SUMMARY}

This article describes how theories of specialists in ludic theory, visual perception and learning, strengthen a domestic playing instrument and transform it into a tool to encourage children who today are growing up in visual society and so help to tune up their senses in order to make a better reading of the world.

\section{KEY WORDS}

Visual perception, visual learning, playful, book production, overall metaphor, symbolic imagination.

\section{INTRODUCCIÓN}

Amalú perdió un botón fue un cuento escrito hace más de tres lustros como regalo para mi hija, entonces con cuatro años de edad. La única expectativa era contar con un instrumento doméstico de juego. Hoy se ha convertido en un material que pretende apoyar a otros padres y madres de familia, para que mientras juegan con sus hijos e hijas, trabajen y estimulen componentes de la percepción visual que inciden sobre el aprendizaje, así pues el material se sustenta en teorías y propuestas de especialistas, formuladas en diferentes disciplinas: lúdica, percepción visual, aprendizaje y producción de libros para niños.

Amalú perdió un botón fue publicado por la editorial Global Editora de Brasil, y es parte del fondo editorial de la Fundación Crianças Criativas con sede en São Paulo, de manera que, por esos giros de la vida, salió a la luz en portugués con el título "Amalú perdeu um botão". En El juego en el proceso de aprendizaje. Capacitación y perfeccionamiento docente (Gandulfo, Taulamet y Lafont, 
2004), Jaime Barylko declara que "[n]ada en educación, es un fin en sí. Todo es un medio" (p.21) y "el juego sería la primera base sobre la que se sustentan las distintas vertientes creativas del hombre" (p.19). Ambas premisas son el cimiento del trabajo que aquí se presenta.

\section{DESARROLLO}

Johan Huizinga (citado por Bernabeu y Goldstein, 2009) configura al ser humano en una dualidad: homo sapiens/homo ludens. El juego es parte de la vida inicial, donde se experimentan el júbilo y la fantasía, aunque su entusiasmo se degrada según se crece y se traslada al ámbito casi exclusivo del deporte competitivo (Gandulfo et al, 2004) por una concepción cultural en la cual "se concibe como sensato y responsable a aquel que, ni juega, ni fantasea" (p.35), porque el adulto debe manifestarse un agente eficaz sobre el mundo real. Asimismo, el juego, pese a su aparente espontaneidad, debe cumplir con dos características esenciales: el definir un contexto o una situación imaginaria y la presencia de reglas, explicitadas o no (Vigotsky, citado por Bernabeu y Goldstein, 2009). De este modo, cuando se retomó el cuento original de esta propuesta, no fue necesario cambiar nada en su estructura para que respetara ambas propiedades.

La historia cuenta la aventura de una niñita llamada Amalú, quien no estrenará su vestido nuevo porque perdió uno de sus botones. Decidida a encontrar un botón similar, emprende un recorrido lúdico y mágico: es sábado por la noche, no hay tiendas abiertas... el único lugar donde podría encontrar un botón, "lógicamente" es en la Granja de Botones, donde estos se "cultivan". Este lugar nunca cierra y allí es siempre de día. El contexto está dado y las reglas son facilitadas por los rasgos del niño mencionados por Franz (2001):

La experiencia escasa, la maleabilidad de conceptos, la permeabilidad de límites entre realidad y fantasía, y entre presente, pasado y futuro, la ignorancia de las reglas de la gramática, la etimología o la redacción, y la falta de prejuicios, desconfianzas y suspicacias (...) [hacen del niño] un destinatario donde toda libertad está permitida. (p. 37)

El promover espacios de aprendizaje con técnicas lúdicas es un valioso recurso para favorecer la apropiación de datos desde la realidad mediante los sentidos, ya que el juego es "un instrumento movilizador y a la vez que este provee a los participantes de un ambiente estimulante para la producción" (Bernabeu y Goldstein, 2009). Amalú perdió un botón propone juegos diversos a lo largo de sus páginas para los niños, mientras que facilita al adulto una guía sencilla para propiciar la interacción con los infantes y con el impreso para que con actitud lúdica promueva la iniciativa en el pequeño para que explore, descubra, elija y active su mundo interior y su curiosidad (Gandulfo et al, 2004).

En este libro se encuentran propuestas de búsqueda, de comparación, de creación, de introspección, juegos para insertarse en un mundo "imposible" y compararlo con realidades subjetivas para rescatar de allí experiencias individuales y colectivas de aprendizaje. Hay actividades a lo largo de las páginas como las que se presentan en las figuras 1,2 y 3 , en los que se debe cuidar la forma de las imágenes, sus colores y diseños interiores e incluso, el número de hoyos para coserlos a la ropa.

El ser humano aprende a través de tres grandes vías: lo visual, lo auditivo y lo táctil-kinésico (Picado, 2007). Al inicio de su vida, los niños y las niñas reciben estímulos para su capacidad de percepción: sonidos, luz, color. Se abren los parámetros de la visión y su cuerpo reacciona a los olores, sabores y texturas; luego viene la capacidad de ejercer la observación, que es el análisis de los objetos con los cinco sentidos ( $p$. 77). Entonces deben desarrollar destrezas, habilidades y conductas psicomotoras específicas en aquellas tres áreas y según su nivel de desarrollo, así será su capacidad de rendimiento $(p, 78)$. 

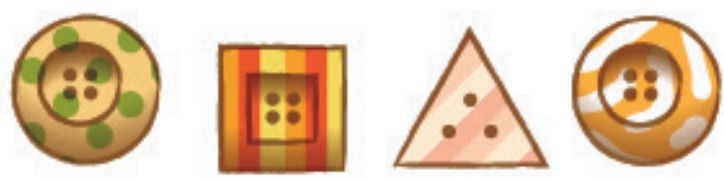

Figura 1. "Encuentra los pares de estos botones en las próximas tres páginas."
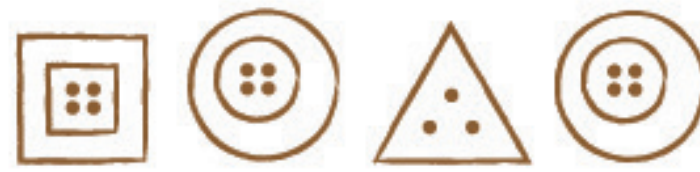

Figura 2. "Colorea estos botones con tus propios diseños."
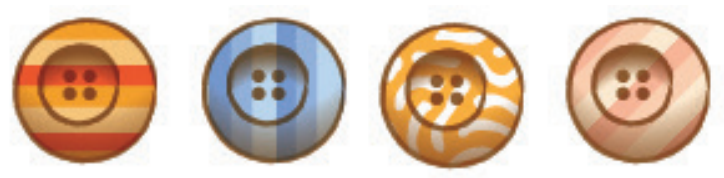

Figura 3. "En las próximas páginas, encuentra botones con los mismos diseños, aunque tengan formas diferentes."

En ambientes lúdicos de aprendizaje, la imagen es un detonador, por lo que según Cruder (2008) puede reforzar u opacar un evento de instrucción debido a una insuficiencia descriptiva, a una ingenuidad expresa o incluso, a un anacronismo estilístico (p.18). La imagen, como las palabras, tiene el potencial de entregar información, datos, conocimientos, experiencias y generar actitudes y valores (Maya, 1995, p.51). Con excepción de su utilización tanto en las ciencias exactas como en matemática, el empleo de imágenes en otras disciplinas cumple mayoritariamente una función ornamental más que didáctica (Roeders, 2006) y desaprovecha su potencial comunicativo y estimulante, su capacidad de impactar y movilizar, de simplificar la descripción de procesos [...] en estrecha vinculación con la transmisión del conocimiento, contribuyendo con la configuración y continuidad de ciertos significados en el proceso de construcción social de la realidad. (Cruder, 2008, p.28).

Por lo anterior, en Amalú perdió un botón, todas las imágenes originales fueron replanteadas y reelaboradas cuidadosamente para complementar el texto con una especie de historia paralela, y detallan lo que las palabras no dicen. Debido a que (...) los lenguajes de la imagen, tienen [...] un amplio apoyo en la percepción visual (Cruder, 2008), las ilustraciones utilizadas son la herramienta justa para el propósito de este material. Se presentan ejemplos en las figuras 4,5 y 6 .

La percepción visual es la capacidad de reconocer y discriminar estímulos visuales, así como interpretarlos y asociarlos con experiencias previas (Frostig, 1983). Esta facultad está presente en toda acción realizada y si se ejecuta correctamente, colaborará con el aprendizaje de la lectura, la escritura y la realización de operaciones aritméticas (p.7).

En nuestro sistema educativo, la visión tiene énfasis a la hora de estudiar: el niño debe leer, copiar y memorizar con la vista (Picado, 2007). Si el niño tuviese, por ejemplo, una dificultad de aprendizaje en este aspecto no se debería necesariamente a alguna limitación física, sino a una ejecución inadecuada de su capacidad visual para aprender (p. 78), ya que la interpretación de los estímulos visuales se lleva a cabo en el cerebro (Frostig, 1983, p.7).

La percepción visual eficiente ayuda al niño a aprender a leer, escribir, utilizar la ortografía, realizar operaciones aritméticas y otras habilidades indispensables para el éxito escolar, por lo tanto Frostig (1983) establece como período normal para el desarrollo máximo de la percepción visual, entre los tres y los siete años aproximadamente. Por esta razón, tanto la historia narrada en el libro como sus ilustraciones, fueron consideradas para el trabajo con niños en ese rango etario. 

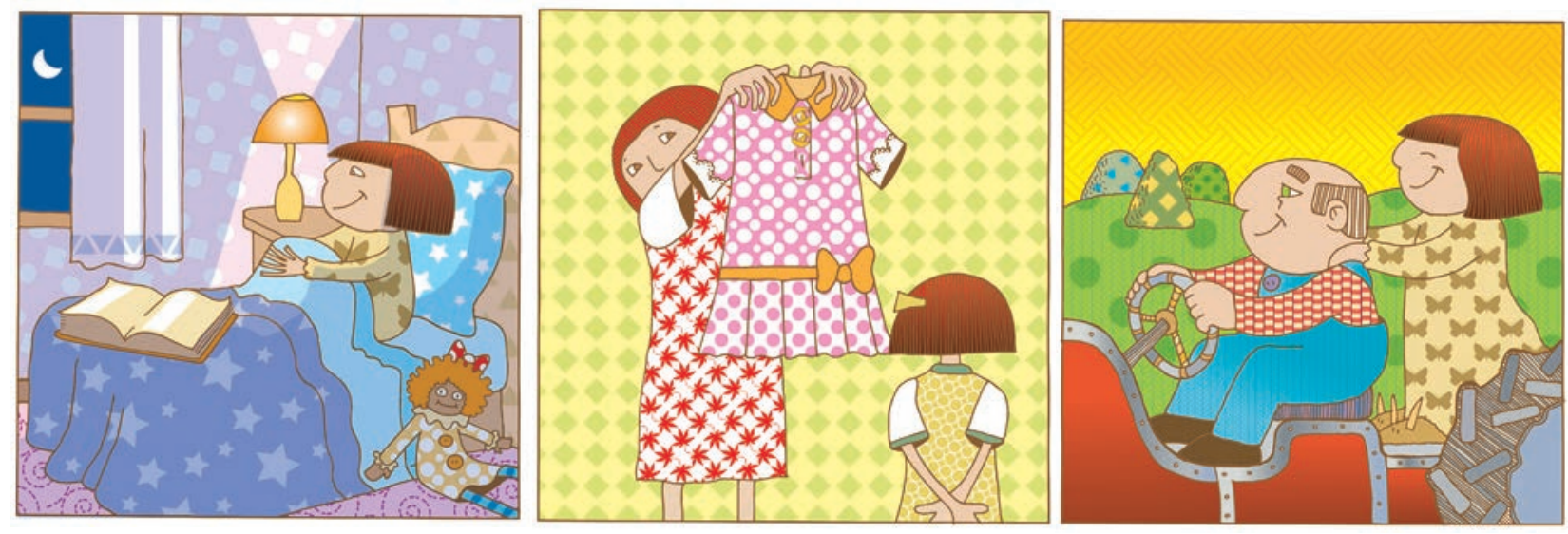

Figuras 4, 5 y 6

Esta misma autora distingue cinco componentes de la percepción visual que inciden sobre el aprendizaje: (1) coordinación visomotriz; (2) percepción de figura-fondo; (3) constancia perceptual; (4) posición en el espacio; (5) relaciones espaciales. La coordinación visomotriz es la capacidad de coordinar la visión con los movimientos del cuerpo o sus partes (Frostig, 1983). Al respecto se aclara que esta particularidad requiere ejercitarse fuera de los recursos que ofrece el libro, pero es necesaria para trabajar las otras cuatro. Así pues, la coordinación visomotriz requiere estimular la armonización muscular, tanto la general como la fina. La primera, se trata de realizar movimientos simultáneos y coordinados con los grandes grupos musculares del cuerpo (p. 30), en la segunda, las actividades propuestas son cortar, colorear, modelar, pintar, enhebrar cuentas y construir estructuras con cubos (pp. 26-27), algunas de las cuales sí se plantean en el libro.

Para la percepción de figura-fondo el cerebro selecciona, entre varios estímulos, un número limitado de ellos y los convierte en su centro de interés. Estos se interpretan como "la figura" mientras los otros no seleccionados se asumen como "el fondo". No es posible percibir con precisión un objeto sino es relacionado con su fondo. El campo visual se divide entonces en dos partes: una a la cual se dirige principalmente la atención y otra que no molesta el interés (Frostig, 1983). En el libro Amalú perdió un botón varias actividades proponen dirigir la atención del infante hacia ciertos componentes de las ilustraciones, mediante preguntas o bien, mediante la búsqueda de detalles que podrían pasar inadvertidos en medio de la profusión de elementos constitutivos del material gráfico.

La constancia perceptual es la capacidad de percibir en un objeto propiedades tales como forma, posición, tamaño, brillo y color, a pesar de la variabilidad de su imagen en la retina" (Frostig, 1983). Para estimular la constancia perceptual, las imágenes de Amalú perdió un botón intentan motivar a la identificación de formas orgánicas y geométricas, sin importar su tamaño, su color o el lugar donde se encuentren posicionadas. También, se proponen actividades para identificar y comparar objetos con tamaño similar, dimensión diferente o formas 
semejantes, o bien comparar figuras como el cuadrado con el rectángulo y el rombo, el óvalo con el círculo e identificarlos en un entorno dado. Estas actividades "(...) ayudan a los niños a discriminar el tamaño, la forma y el color, y también a reconocer objetos tridimensionales dibujados en un plano bi-dimensional y viceversa" (Frostig, 1983).

La posición en el espacio se refiere a la relación de un objeto en el entorno respecto al observador; es decir, cuando se habla de la posición en el espacio, siempre el cuerpo del observador es el centro, de manera que percibe los objetos respecto a sí mismo, bien sea delante, detrás, por encima o debajo, a la izquierda o a la derecha de él. Los niños deben aprender a diferenciar con claridad la orientación derechaizquierda en su propio cuerpo y luego con objetos en el espacio. En varias actividades que propone el material que se describe, se les solicita ubicar objetos en las ilustraciones que están "a la izquierda de" o "a la derecha de" determinada figura o personaje. También, en él se pide ubicar objetos que están "encima", "debajo", "dentro", "fuera", "delante" o "detrás" de otros. En algunos ejercicios propuestos de inversión y rotación, los pequeños interlocutores deberán identificar figuras en posiciones diferentes y compararlas para ubicar diferencias y similitudes.

Las Relaciones espaciales se refieren a la capacidad de quien observa para percibir la posición de varios objetos en relación entre ellos y consigo mismo. En este caso, se debería poder observar cualquier cantidad de partes diferentes y relacionarlas unas con otras, mientras todas reciben la misma atención. Las actividades para las relaciones espaciales son muy similares a las propuestas para la estimulación de la percepción de posición en el espacio, pero involucran, además, cualidades de referencia como el color, el tamaño y el concepto de simetría.

En el libro Amalú perdió un botón, toda la propuesta se basa en metáforas porque "(I) la magia de las metáforas no consiste en otra cosa que proporcionar un momento inicial de motivación, facilitar el surgimiento de alternativas de acción o ilustrar con pinceladas iluminadoras un objetivo para mantenerlo en el punto de mira" (Owen, 2003).

El concepto de metáfora no pertenece en exclusiva al ámbito del lenguaje, más bien es parte de la imaginación simbólica, está inserto en la vivencia cotidiana y facilita su aplicación en espacios diferentes al de la palabra, con una utilización más extensa y relevante (Ochoa, 1997). El pensamiento metafórico se describe como una mezcla conceptual que comprende la observación, clasificación y pensamiento conceptual (Fauconnier y Turner, citados por Serig, 2006). La percepción metafórica es esencial para elaborar conocimiento sobre el mundo y el ser y forma parte de las condiciones de la percepción misma (Ochoa, 1997).

Al respecto, Gardner (1996, p. 240) dice que "prácticamente todos los conceptos que vale la pena comprender pueden conceptualizarse de muchas maneras, así como representarse y enseñarse de muchas maneras también" y Susanne Langer (cit. por Navarro y Lozano, 1999, p. 2) manifiesta que el origen del pensamiento metafórico se encuentra en la naturaleza propia de la percepción, en la abstracción visual, entonces la metáfora es una de las más importantes evidencias del poder de la mente para usar símbolos presentacionales, por lo que considera la percepción visual como un proceso de abstracción.

Cuando se utiliza el concepto de metáfora en el ámbito de lo visual, se representa un objeto, una idea o un concepto con una imagen, quizás no necesariamente denotativa, pero cuyo significado y funcionalidad pueden reconocerse. Entonces, para poder consensuar el contenido textual con la propuesta gráfica, se aplicó el concepto de metáfora global, que "es una metáfora que nos da el marco para todas las otras metáforas del sistema." (Lorés y Gimeno, 2001), esta facilita no solo la representación de las ideas, sino la lógica de su contexto. 
Por lo anterior, el personaje principal del libro realiza una búsqueda, ya que ha perdido algo (un botón) y para encontrarlo hace un recorrido en un sitio donde los objetos se cultivan y crecen (una granja). Dado que la historia inicia cuando la madre de Amalú cose un hermoso vestido para su hija, todas las imágenes se relacionan con procesos u objetos de costura: en la granja de botones, las gallinas son alfileteros, las ovejas son ovillos de lana, los alfileres con cabezas de colores crecen a la orilla del lago y los botones se cultivan en extensos sembradíos, en multiplicidad de formas, tamaños y colores.

Para Field (2002) un guión "es una historia contada en imágenes. Es como un nombre: trata de una persona o personas en un lugar o lugares, haciendo una 'cosa'. Todos los guiones cumplen esta premisa básica." Este reconocido guionista estadounidense reduce la narración de una historia a tres momentos clave: planteamiento, confrontación y resolución (p.13). Amalú perdió un botón descansa en esa elemental estructura: a) en el cálido entorno de su casa: un sábado por la tarde la madre de la niña cose afanosa un lindo vestido, el cual Amalú estrenará el domingo, en la fiesta de cumpleaños de su primo; b) finalizado el vestido, descubren alarmadas un botón faltante. En la casa no hay otro juego de botones que combine con el traje y ya es muy tarde para salir a las tiendas a comprarlo; c) Amalú resuelve acudir a las Hermanas Hilvanez (Dedalia y Filigrana), dueñas de una Granja de Botones donde al final de un recorrido con el granjero Cordelio encontrará el botón, aunque en el lugar menos esperado.

\section{CONCLUSIONES}

La falta de prejuicios ya mencionada y la necesidad de juego hacen del niño "(...) una fuente de recursos todavía insuficientemente explorados y explotados para la expresión artística de esos adultos híbridos que somos los autores de libros infantiles." (Franz, 2001, p. 37). Este antecedente fue la motivación para combinar la habilidad para el dibujo y la ilustración, con una tímida necesidad de escribir, compaginándolas con la solidaria intención de transmitir a otros padres y madres de familia la urgente necesidad de estimular a sus niños y niñas, quienes están creciendo en una sociedad pródigamente visual, para afinar sus sentidos y apropiarse del mundo en mejor forma de lo que lo hicimos nosotros.

\section{BIBLIOGRAFÍA}

Bernabeu, N., Goldstein, A. (2009). Creatividad y aprendizaje. El juego como herramienta pedagógica. Madrid: Narcea.

Cruder, G. (2008). La educación de la mirada. Sobre los sentidos de la imagen en los libros de texto. Buenos Aires: Stella/La Crujía.

Field, S. (2002). El libro del guión. Fundamentos de la escritura de guiones. Madrid: Plot Ediciones.

Franz, J. (2001). La literatura infantil: un oficio de centauros y sirenas. Buenos Aires: Lugar Editorial.

Frostig, M. (1983). Figuras y formas. Guía del maestro. México: Panamericana.

Gandulfo, M., Taulamet, M., Lafont, E. (2004). El juego en el proceso de aprendizaje. Buenos Aires: Stella/La Crujía.

Gardner, H. (1996). Inteligencias múltiples. La teoría en la práctica. Barcelona: Paidós.

Lorés, J.; Gimeno, J. (2001). Metáforas, estilos y paradigmas. Recuperado de www.aipo.es/libro/ doc/ozmetafo.doc

Maya, A. (1995). Módulo para la ilustración de textos escolares (II). En Proyecto Unesco/Alemania, 507/RLA/11(Ed.) Elaboración de textos y materiales de lectura para la educación básica en Centroamérica y Panamá. Sanfé de Bogotá/ Panamericana.

Navarro, R.; Lozano, H. (1999). Metáforas visuales y representación. Recuperado de http://cognitiva.univalle.edu.co/archivos/grupo\%2ocognicion\%20y\%2odesarrollo/publicaciones/rpuche/Ponencia\%20Met\%E1foras\%2ovisual\%20 y\%2orepresentac.pd 
Owen, N. (2003). La magia de la metáfora. 77 relatos breves para educadores, formadores y pensadores. Bilbao: Desclée de Brouner.

Picado, K. (2007). El arte de aprender. Libro de actividades. San José: UNED-Grupo Nación.

Picado, K. (2007). El arte de aprender. Una guía formativa para el hogar y la escuela. San José: UNED-Grupo Nación.
Roeders, P. (2006). Aprendiendo juntos. Lima: Alfaomega.

Serig, D. (2006). A Conceptual Structure of Visual Metaphor. Studies in Art Education; Spring 2006; 47, 3; ProQuest Education Journals. p. 229

Villalobos, D. (2013). Amalú perdeu um botão. Global Editora: São Paulo 
